\title{
KEANEKARAGAMAN TANAMAN PEKARANGAN DI DESA TAMBUSAI TIMUR KECAMATAN TAMBUSAI KABUPATEN ROKAN HULU PROVINSI RIAU
}

\author{
Devi Yulianti ${ }^{1 *}$, Arief Anthonius Purnama ${ }^{1}$, Eti Meirina Brahmana ${ }^{1}$ \\ ${ }^{I}$ Program Studi Pendidikan Biologi Fakultas Keguruan Dan Ilmu Pendidikan \\ Universitas Pasir Pengaraian \\ Jl. Tuanku Tambusai Kumu Desa Rambah Kecamatan Rambah Hilir. Pasir Pengaraian \\ *Email: deviyulianti004@gmail.com
}

\begin{abstract}
This research purpose to know of wide diversity of the yard in the Village of Tambusai Timur District of Tambusai Rokan Hulu Regency Province of Riau. This research have done on February until April 2018 that used direct observation (server inventarisasi). The plant that can be identify the researcher describ them with character of morfologyzal the source of reference the result of this research. Get the poin and indeksof wide diversity of the yard the telatively high on stasiun one $(4,65)$, stasiun two $(4,90)$ and stasiun three $(3,72)$. That get 53 family, 96 genus and 107 species. The plant have habitus tree, shrub shaped or herbs that in use for ornamental plant, fruit and, food and medicine. All the species can get from the family Apocynaceae, Araceae, Euphorbiaceae, Myrtaceae, Palmae, Rutaceae and Zingeberaceae.
\end{abstract}

Keywords: Yard, Diversity, Tambusai Timur Village.

\section{PENDAHULUAN}

Indonesia merupakan negara yang beriklim tropis dan memiliki tingkat keanekaragaman tumbuhan. Selain suhu tropis Indonesia juga memiliki PH tanah yang sangat baik sebagai tempat tumbuhnya berbagai macam tumbuhan (Yarni, Yesnibar, \& Bangun, 2012).

Pekarangan merupakan lahan yang tersedia diantara rumah atau gedung. Pekarangan sering juga diartikan sebagai Ruang Terbuka Hijau (RTH) atau lahan kosong di sekitar rumah yang biasanya ditanami berbagai jenis tanaman (Pendong \& Arrinjani, 2004). Pekarangan rumah merupakan habitat berbagai jenis tanaman untuk tumbuh. Ukuran pekarangan rumah di desa bisa sangat beragam, terutama dipengaruhi oleh aspek-aspek sosial dan ekonomi dari pemilik rumah.

Pekarangan rumah memiliki fungsi sebagai berikut yaitu: 1) Sebagai penghasil bahan pangan tambahan selain sawah dan ladang (padi, jagung, singkong), yakni berupa lauk-pauk (sayuran) dan buah-buahan, 2) Penghasil uang tambahan ataupun dapat mengurangi belanja dapur sehingga disebut juga sebagai lumbung hidup (kelapa, pisang, nangka, dan lain-lain), 3) Sebagai penghasil bumbu-bumbuan, rempah-rempah, wangiwangian dan obat-obatan sehingga disebut pula sebagai apotik hidup, 4) Sebagai penghasil bahan perumahan, seperti bambu, jeujing, dan lain-lain, 5) Sebagai penghasil kayu bakar, terutama dari sisa-sisa pemangkasan pohon, 6) Sebagai penghasil bahan baku untuk industri kerajinan atau industri kecil (home industry), misalnya bambu untuk kipas, kukusan dan anyaman lain; batok kelapa untuk irus dan lainlain (Zulkarnain, 2010). Sedangkan menurut Yarni. et al. (2012), pekarangan mempunyai fungsi ekonomi, keindahan, kesehatan dan pentilasi. 
Pekarangan masih banyak rumah penduduk yang hanya sekarang ditumbuhi oleh rumput yang tidak memiliki nilai ekonomis dan tidak memiliki nilai estetika. Sedangkan sebagian masyarakat sudah memanfaatkan pekarangan rumahnya untuk ditanami tanaman yang bermanfaat dan bernilai ekonomis. Pemanfaatan lahan pekarangan untuk ditanami berbagai jenis tumbuhan perlu dilakukan agar keanekaragaman hayati pada lahan pemukiman tetap tinggi dan produksi pertanian dapat dipertahankan atau menaikkan daya dukung lingkungan melalui penghijauan dalam sistem pekarangan. Dikarenakan belum adanya informasi mengenai tanaman pekarangan ini, maka perlu dilakukan penelitian ini.

\section{METODE PENELITIAN}

Penelitian dilakukan secara acak dengan pertimbangan sampel (purposive random sampling) dengan kategorisasi dilakukan berdasarkan luas pekarangan. Pengamatan dan pengambilan spesimen tanaman dilakukan dengan mengoleksikan langsung tanaman di lapangan, tanaman yang tercuplik diidentifikasi dengan buku acuan collection of illustrated tropical plants (Corner \& Watanabe, 1969). Tanaman yang teridentifikasi di lapangan tidak diambil spesimennya sedangkan tanaman yang tidak teridentifikasi di lapangan akan diambil spesimennya dan dibawa ke laboratorium untuk dijadikan herbarium. Pengoleksian tanaman dilakukan pada tiga stasiun. Pada masingmasing stasiun diambil 15 sampel pekarangan yaitu 5 sampel untuk tanaman strata satu (tinggi tanaman kurang atau sama dengan $1 \mathrm{M}$ ), 5 sampel untuk tanaman strata dua ( tinggi tanaman 1-3 M) dan 5 sampel untuk tanaman strata 3 (tinggi tanaman lebih dari $3 \mathrm{M}$ ) (Indriyanto, 2006).

Alat yang digunakan untuk penelitian ini adalah kamera, meteran, GPS, dan alat tulis. Keanekaragaman tanaman pekarangan dianalisis dengan menggunakan rumus indeks keanekaragaman jenis menurut (Odum, 1998) sebagai berikut:

$$
\mathrm{H}^{\prime}=-\sum \text { pi ln pi }
$$

Keterangan:

$\mathrm{H}^{\prime}$ : Indeks keanekaragaman Odum

$\mathrm{Pi}$ : Peluang untuk kepentingan setiap jenis (ni/N)

ni : Nilai kepentingan setiap jenis ( jumlah individu tiap jenis)

$\mathrm{N}$ : Nilai kepentingan total (jumlah total semua individu)

$\sum$ : Jumlah

Hasil H' dihubungkan dengan kategori indeks keanekaragaman terdiri dari beberapa kreteria:

$>3,00 \quad$ : Keanekaragaman tinggi

1,00-3,00 : Keanekaragaman sedang

$<1,00 \quad$ : Keanekaragaman rendah

\section{HASIL DAN PEMBAHASAN}

Penelitian yang telah dilakukan di Desa Tambusai Timur Kecamatan Tambusai Kabupaten Rokan Hulu Provinsi Riau didapatkan tanaman pekarangan sebanyak 107 spesies, 96 genus dan 53 famili dengan 4.913 individu yang diperoleh dari 3 stasiun di Desa Tambusai Timur dapat disajikan pada Tabel 1.

Indeks keanekaragaman ( $\left.\mathrm{H}^{\prime}\right)$ tanaman pekarangan yang diperoleh dari tiga stasiun penelitian di Desa Tambusai Timur adalah Stasiun satu berjumlah 1.645 individu dengan indeks keanekaragaman sebesar $(4,65)$, stasiun 2 berjumlah 1.929 individu dengan indeks keanekaragaman sebesar $(4,90)$ dan stasiun 3 dengan jumlah individu 1,339 dengan indeks keanekaragaman sebesar $(3,72)$. Berdasarkan indeks keanekaragaman tanaman yang diperoleh dari tiga stasiun memiliki keanekaragaman yang tergolong tinggi. Dari ke 3 stasiun yang telah diteliti, tingkat keanekaragaman tanaman yang paling tinggi terdapat pada stasiun 2. Jumlah spesies yang ditemukan pada stasiun 2 sebanyak 82 spesies dengan jumlah individu 1.929 dan jumlah total indeks keanekaragaman 4,90 dihubungkan dengan kategori indeks keanekaragaman $>3,00$ keanekaragaman tinggi. dapat disajikan pada Tabel 2. Hal ini dikarenakan pada stasiun 2 memiliki pekarangan yang lebih luas dibandingkan stasiun 1 dan 3 , sehingga semakin 
luas pekarangan maka semakin banyak jenis tanaman yang ditanami oleh masyarakat dipekarangan (Pendong \& Arrinjani, 2004), menyatakan bahwa pertambahan luas lahan efektif cendrung meningkatkan jumlah jenis dan individu tanaman pekarangan.

Indeks keanekaragaman dapat digunakan sebagai bio indikator yang menggambarkan dukungannya terhadap kestabilan sebuah ekosistem. Besar kecilnya nilai indeks keanekaragaman tanaman di pekarangan dapat memberi petunjuk seberapa besar daya dukungan ekosistem terhadap pemukiman. (Odum, 1998) menyatakan bahwa keaneka-ragaman jenis merupakan fungsi dari keanekaragaman ruang tumbuh. Makin besar keanekaragaman ruang tumbuh akan semakin besar pula keanekaragaman jenis. Apabila suatu daerah hanya didominasi oleh jenis-jenis tertentu saja maka daerah tersebut memiliki keanekaragaman jenis yang rendah. Pekarangan merupakan lingkungan buatan sehingga tumbuhan yang ada didalamnya cenderung sengaja ditanam sesuai dengan keinginan pemilik pekarangan. Umumnya pemilik pekarangan menanam pekarangan dengan tumbuhan yang bervariasi jenis maupun manfaatnya. Berdasarkan hal tersebut maka disuatu pekarangan tidak ada penguasaan oleh satu jenis tumbuhan. Dengan nilai keanekaragaman yang tinggi maka komunitas tumbuhan tersebut semakin stabil sehingga mampu untuk bersaing dalam mengambil nutrisi dan unsur hara yang menunjukkan adanya kestabilan suatu komunitas (Mukarlina., Linda, \& Nurlaila, 2014).

Tabel 1. Keanekaragaman tanaman yang ditemukan di Desa Tambusai Timur Kecamatan Tambusai Kabupaten Rokan Hulu Provinsi Riau.

\begin{tabular}{|c|c|c|c|c|c|c|c|c|c|}
\hline \multirow{2}{*}{ No } & \multicolumn{3}{|c|}{ Taksonomi } & \multirow{2}{*}{ - Nama Lokal } & \multirow{2}{*}{ Strata } & \multicolumn{3}{|c|}{ Stasiun } & \multirow{2}{*}{ Jumlah } \\
\hline & Famili & Genus & Spesies & & & 1 & 2 & 3 & \\
\hline 1. & Apocynaceae & Catharanthus & $\begin{array}{l}\text { Catharanthus } \\
\text { roseus }\end{array}$ & Tapak dara & 1 & 3 & 7 & - & 10 \\
\hline 2. & & Plumeria & $\begin{array}{l}\text { Plumeria } \\
\text { acutifolia }\end{array}$ & $\begin{array}{l}\text { Kamboja } \\
\text { putih }\end{array}$ & 2 & 2 & 3 & - & 5 \\
\hline 3. & & & Plumeria alba & $\begin{array}{l}\text { Bunga mente } \\
\text { ga }\end{array}$ & 2 & 5 & 8 & 8 & 21 \\
\hline 4. & & $\begin{array}{l}\text { Tabernaemonth } \\
\text { ana }\end{array}$ & $\begin{array}{l}\text { Tabernaemontana } \\
\text { dicthoma }\end{array}$ & Tabernoa & 1 & 6 & 18 & 13 & 37 \\
\hline 5. & & Allamanda & $\begin{array}{l}\text { Allamanda cathart } \\
\text { ica }\end{array}$ & t Alamanda & 2 & 8 & 11 & 23 & 42 \\
\hline 6. & & Cerbera & Cebera manghas & Bintagur & $\begin{array}{c}2 \text { dan } \\
3\end{array}$ & - & 3 & - & 3 \\
\hline 7. & & Adenium & Adenium coetanum & $\begin{array}{l}n \text { Kamboja } \\
\text { jepang }\end{array}$ & 1 & - & - & 10 & 10 \\
\hline 8. & & Evertamia & $\begin{array}{l}\text { Ervatamia } \\
\text { divaricata }\end{array}$ & Mondokaki & 2 & - & 3 & - & 3 \\
\hline 9. & Amaranthaceae & Celosia & Celosia cristata & $\begin{array}{l}\text { Jenggger } \\
\text { ayam }\end{array}$ & 1 & - & 7 & - & 7 \\
\hline 10. & & Allamania & Allmania nodiflora & $\begin{array}{l}a \text { Bunga } \\
\text { kancing }\end{array}$ & 1 & 8 & - & 3 & 11 \\
\hline 11. & & Altthenanthera & $\begin{array}{l}\text { Althenanthera } \\
\text { amoena }\end{array}$ & Bayam hias & 1 & - & - & 15 & 15 \\
\hline 12. & Agaveceae & Sansevieria & $\begin{array}{l}\text { Sansevieria trifasc } \\
\text { ata }\end{array}$ & iLidah mertua & 1 & 8 & 5 & 7 & 20 \\
\hline 13. & & Furcraea & Furcraea foitida & Lili paris & 1 & - & - & 6 & 6 \\
\hline 14. & Amryllidae & Crimun & Crinum asianticum & $n$ Bakung & 1 & - & 8 & - & 8 \\
\hline 15. & & & Crinum latifolium & Amarilis & 1 & 9 & - & - & 9 \\
\hline
\end{tabular}


Yulianti, D., Purnama, AA., Brahmana, EM. 2018. Keanekaragaman Tanaman Pekarangan di Desa Tambusai Timur Kecamatan Tambusai Kabupaten Rokan Hulu Provinsi Riau. Sainstek : Jurnal Sains dan Teknologi. 10 (1) : 13-19

\begin{tabular}{|c|c|c|c|c|c|c|c|c|c|}
\hline \multirow{2}{*}{ No } & \multicolumn{3}{|c|}{ Taksonomi } & \multirow{2}{*}{ - Nama Lokal } & \multirow{2}{*}{ Strata } & \multicolumn{3}{|c|}{ Stasiun } & \multirow{2}{*}{ Jumlah } \\
\hline & Famili & Genus & Spesies & & & 1 & 2 & 3 & \\
\hline 16. & Annonaceae & Polyanthia & $\begin{array}{l}\text { Polyalthia } \\
\text { longifolia }\end{array}$ & $\begin{array}{l}\text { Glondokan } \\
\text { tiang }\end{array}$ & $\begin{array}{c}2 \text { dan } \\
3\end{array}$ & 2 & - & 10 & 12 \\
\hline 17. & Araceae & Colocasia & $\begin{array}{l}\text { Colocasia escule } \\
\text { nta }\end{array}$ & Keladi & 1 & 10 & 15 & 15 & 40 \\
\hline 18. & & Dieffenbachia & $\begin{array}{l}\text { Dieffenbachia ma } \\
\text { gnifica }\end{array}$ & $\begin{array}{l}\text { Daun } \\
\text { bahagia }\end{array}$ & 1 & 5 & 5 & 6 & 16 \\
\hline 19. & & Caladium & $\begin{array}{l}\text { Caladium bocolo } \\
r\end{array}$ & Keladi merah & 1 & - & 15 & - & 15 \\
\hline 20. & & Philodendrom & $\begin{array}{l}\text { Philodendrom ac } \\
\text { cocardium }\end{array}$ & Kuping gajah & 1 & 15 & 8 & 3 & 26 \\
\hline 21. & & Aglaonema & $\begin{array}{l}\text { Aglaonema } \\
\text { commitatum }\end{array}$ & Sri rezeki & 1 & 25 & 31 & 17 & 73 \\
\hline 22. & & Zamioculcas & $\begin{array}{l}\text { Zamioculcas } \\
\text { zamiifolia }\end{array}$ & Bunga dolar & 1 & 17 & 19 & 5 & 41 \\
\hline 23. & & Anthurium & $\begin{array}{l}\text { Anthurium } \\
\text { schlechtendalii }\end{array}$ & $\begin{array}{l}\text { Gelombang } \\
\text { cinta }\end{array}$ & 1 & - & - & 19 & 19 \\
\hline 24. & - Achantacea & Thunbergia & $\begin{array}{l}\text { Thunbergia } \\
\text { erecta }\end{array}$ & Thunbergia & 2 & 7 & 12 & 6 & 25 \\
\hline 25 . & & Reulia & $\begin{array}{l}\text { Reulia } \\
\text { malacosperma }\end{array}$ & Reulia & 1 & 40 & 63 & - & 103 \\
\hline 26. & - Anacardiaceae & Mangifera & Mangifera indica & Mangga & $\begin{array}{c}2 \text { dan } \\
3\end{array}$ & 32 & 37 & 27 & 96 \\
\hline 27. & Bombacaceae & Durio & Durio zibethinus & Durian & 3 & 17 & 25 & 31 & 73 \\
\hline 28. & Bromeliacea & Annanas & Annanas comosus & Nanas & 1 & 45 & 52 & 29 & 126 \\
\hline 29. & Convovulaceae & Ipomoea & Ipomoea batatas & Ubi rambat & 1 & 30 & 30 & - & 60 \\
\hline 30. & Combretaceae & Terminalia & $\begin{array}{l}\text { Terminalia } \\
\text { catappa }\end{array}$ & Ketapang & 3 & 15 & 22 & 27 & 64 \\
\hline 31. & Cycadaceae & Cycas & Cycas rumphii & Pakis haji & 2 & 15 & - & - & 15 \\
\hline 32. & Commelinaceae & Rhoeo & Rhoeo discolor & Adam hawa & 1 & 18 & 24 & 28 & 70 \\
\hline 33. & Cannaceae & Canna & Canna hybryda & Kana & 2 & 9 & 14 & 17 & 40 \\
\hline 34. & - Campanulaceae & Laurentia & $\begin{array}{l}\text { Laurentia } \\
\text { longiflora }\end{array}$ & Kitolod & 1 & - & 35 & 43 & 78 \\
\hline 35. & Caricaeae & Carica & Carica papaya & Pepaya & 2 & 23 & 10 & 13 & 46 \\
\hline 36. & - Crassulaceae & Bryophyllum & $\begin{array}{l}\text { Bryophyllum } \\
\text { pinnatum }\end{array}$ & Cocor bebek & 1 & 40 & 52 & 14 & 106 \\
\hline 37. & Composite & Zinnia & Zinnia linearis & Zinnia & 1 & 28 & 53 & 26 & 107 \\
\hline 38. & & Helianthus & Helianthus annus & $\begin{array}{l}\text { Bunga } \\
\text { matahari }\end{array}$ & 2 & 17 & - & - & 17 \\
\hline 39. & & Gynura & $\begin{array}{l}\text { Gynura } \\
\text { procumbens }\end{array}$ & $\begin{array}{l}\text { Sambung } \\
\text { nyawa }\end{array}$ & 2 & - & 17 & - & 17 \\
\hline 40. & & Cosmos & $\begin{array}{l}\text { Cosmos } \\
\text { sulphureus }\end{array}$ & Knikir & 1 & 80 & 75 & 17 & 172 \\
\hline 41. & - Cactaceae & Cereus & $\begin{array}{l}\text { Cereus } \\
\text { Tentrogonus }\end{array}$ & Kaktus & 2 & 16 & 8 & - & 24 \\
\hline 42. & Cupressaceae & Thuja & Thuja orienthalis & Cemara kipas & 2 & 6 & 3 & - & 9 \\
\hline 43. & podocarpoceae & Dacrydium & $\begin{array}{l}\text { Dacrydium } \\
\text { elatum }\end{array}$ & $\begin{array}{l}\text { Cemara } \\
\text { norfolk }\end{array}$ & 3 & 5 & 13 & - & 18 \\
\hline 44. & Elaeocarpoceae & Muntingia & $\begin{array}{l}\text { Muntingia } \\
\text { calabura }\end{array}$ & Ceri & $\begin{array}{c}2 \text { dan } \\
3\end{array}$ & - & 2 & - & 2 \\
\hline 45. & Euphorbiaceae & Manihot & $\begin{array}{l}\text { Manihot } \\
\text { ultilissima }\end{array}$ & Singkong & 2 & 43 & 80 & 77 & 200 \\
\hline
\end{tabular}


Yulianti, D., Purnama, AA., Brahmana, EM. 2018. Keanekaragaman Tanaman Pekarangan di Desa Tambusai Timur Kecamatan Tambusai Kabupaten Rokan Hulu Provinsi Riau. Sainstek : Jurnal Sains dan Teknologi. 10 (1) : 13-19

\begin{tabular}{|c|c|c|c|c|c|c|c|c|}
\hline \multicolumn{3}{|c|}{ Taksonomi } & \multirow{2}{*}{ - Nama Lokal } & \multirow{2}{*}{ Strata } & \multicolumn{3}{|c|}{ Stasiun } & \multirow{2}{*}{ Jumlah } \\
\hline Famili & Genus & Spesies & & & 1 & 2 & 3 & \\
\hline 46. & Euphorbia & $\begin{array}{l}\text { Euphorbia } \\
\text { neriifolla }\end{array}$ & Sudu- sudu & 1 & 27 & 49 & 22 & 98 \\
\hline 47. & Ricinus & $\begin{array}{l}\text { Ricinus } \\
\text { communis }\end{array}$ & Jarak & 2 & 9 & 7 & 3 & 19 \\
\hline 48. & Hevea & $\begin{array}{l}\text { Hevea } \\
\text { bransiliensis }\end{array}$ & Karet & 3 & 5 & - & - & 5 \\
\hline 49. lenguninoseae & pithecallobium & $\begin{array}{l}\text { Pithecellobium } \\
\text { lobatum }\end{array}$ & Jengkol & 3 & 10 & 17 & 13 & 40 \\
\hline 50. & Leucaena & $\begin{array}{l}\text { Leucaena } \\
\text { leucocephala }\end{array}$ & Petai cina & 3 & 3 & 1 & - & 4 \\
\hline 51. & Delonix & Delonix regia & plamboyan & 3 & - & - & 9 & 9 \\
\hline 52. Guttiferae & Garcinia & $\begin{array}{l}\text { Garcinia } \\
\text { mangostana }\end{array}$ & Manggis & 3 & 12 & 29 & 33 & 74 \\
\hline 53. Graminaea & Saccharum & $\begin{array}{l}\text { Saccharum } \\
\text { officinarum }\end{array}$ & Tebu & 2 & 44 & 63 & 51 & 158 \\
\hline 54. & Cymbopogom & $\begin{array}{l}\text { Cymbopogon } \\
\text { citratus }\end{array}$ & Serai & 1 & 82 & 90 & 72 & 244 \\
\hline 55. & Bambusa & $\begin{array}{l}\text { Bambusa } \\
\text { multiplex }\end{array}$ & Bambu hias & 1 & 97 & - & - & 97 \\
\hline 56. Labiate & Ocimun & $\begin{array}{l}\text { Ocimun } \\
\text { citriodorum }\end{array}$ & Kemangi & 1 & - & 37 & - & 37 \\
\hline 57. & Orthosiphon & $\begin{array}{l}\text { Orthosiphon } \\
\text { grandillorus }\end{array}$ & Kumis kucing & 1 & 6 & 11 & 9 & 26 \\
\hline 58. Liliaceae & Aloe & Aloe vera & Lidah buaya & 1 & 13 & 17 & 21 & 51 \\
\hline 59. Myrtaceae & Psidium & Psidium guajava & Jambu biji & $\begin{array}{c}2 \text { dan } \\
3\end{array}$ & 9 & 7 & 11 & 27 \\
\hline 60. & Syzygium & $\begin{array}{l}\text { Syzigium } \\
\text { malaccensis }\end{array}$ & Jambu bol & 2 & - & 5 & 13 & 18 \\
\hline 61. & & $\begin{array}{l}\text { Syzigium aquea B } \\
\text { urm }\end{array}$ & Jambu air & $\begin{array}{c}1,2 \\
, 3\end{array}$ & 16 & 21 & 17 & 54 \\
\hline 62. & & $\begin{array}{l}\text { Syzigium } \\
\text { polyantha }\end{array}$ & Daun salam & 2 & 3 & 9 & 7 & 19 \\
\hline 63. & & Syzygium oleana & Pucuk merah & 2 & 15 & - & 17 & 32 \\
\hline 64. Mellaceae & Lansium & $\begin{array}{l}\text { Lansium } \\
\text { domesticum }\end{array}$ & Duku & 3 & 5 & 12 & - & 17 \\
\hline 65. Malvaceae & Hibiscus & Hibiscus tiliaceus & Waru & 2 & 3 & - & 13 & 16 \\
\hline 66. & & $\begin{array}{l}\text { Hibiscus } \\
\text { rosasinensis }\end{array}$ & $\begin{array}{l}\text { Kembang } \\
\text { sepatu }\end{array}$ & $\begin{array}{l}1 \text { dan } \\
2\end{array}$ & 23 & 17 & - & 40 \\
\hline 67. Musaceae & Heliconia & $\begin{array}{l}\text { Heliconia } \\
\text { psittacorum }\end{array}$ & Pisang bali & $\begin{array}{l}1 \text { dan } \\
2\end{array}$ & 14 & - & - & 14 \\
\hline 68. & Musa & Musa paradisiaca & Pisang & 2 & 35 & 42 & 45 & 122 \\
\hline 69. Moringaceae & Moringa & $\begin{array}{l}\text { Moringa } \\
\text { pterygosperma }\end{array}$ & Kelor & 2 & - & 4 & - & 4 \\
\hline 70. Moraceae & Artocarpus & $\begin{array}{l}\text { Artocarpus } \\
\text { helerophyllus }\end{array}$ & Nangka & $\begin{array}{c}2 \text { dan } \\
3\end{array}$ & 20 & 30 & 11 & 61 \\
\hline 71. Ngctaginacea & Boungainvillea & $\begin{array}{l}\text { Bougainvillea } \\
\text { spectabilis }\end{array}$ & Bunga kertas & $\begin{array}{l}1 \text { dan } \\
2\end{array}$ & 42 & 35 & 27 & 104 \\
\hline 72. Oxalidaceae & Averrhoa & Averrhoa bilimbi & $\begin{array}{l}\text { Blimbing } \\
\text { wuluh }\end{array}$ & 3 & - & 4 & - & 4 \\
\hline 73. & & $\begin{array}{l}\text { Averrhoa } \\
\text { carambola }\end{array}$ & $\begin{array}{l}\text { Blimbing } \\
\text { manis }\end{array}$ & 3 & 3 & - & - & 3 \\
\hline
\end{tabular}


Yulianti, D., Purnama, AA., Brahmana, EM. 2018. Keanekaragaman Tanaman Pekarangan di Desa Tambusai Timur Kecamatan Tambusai Kabupaten Rokan Hulu Provinsi Riau. Sainstek : Jurnal Sains dan Teknologi. 10 (1) : 13-19

\begin{tabular}{|c|c|c|c|c|c|c|c|c|}
\hline \multicolumn{3}{|c|}{ Taksonomi } & \multirow{2}{*}{ - Nama Lokal } & \multirow{2}{*}{ Strata } & \multicolumn{3}{|c|}{ Stasiun } & \multirow{2}{*}{ Jumlah } \\
\hline Famili & Genus & Spesies & & & 1 & 2 & 3 & \\
\hline 74. Oleaceae & Jasminum & $\begin{array}{l}\text { Jasminum } \\
\text { sambac }\end{array}$ & Melati & $\begin{array}{c}1 \text { dan } \\
2\end{array}$ & - & - & 7 & 7 \\
\hline 75. Orchidaceae & Spathoglottis & $\begin{array}{l}\text { Spathoglottis } \\
\text { plicata }\end{array}$ & Anggrek & 1 & 3 & - & 7 & 10 \\
\hline 76. Palmae & Areca & Areca catechu & Pinang & 3 & 19 & 21 & 13 & 53 \\
\hline 77. & Cocos & Cocos nucifera & Kelapa & $\begin{array}{c}2 \text { dan } \\
3\end{array}$ & 33 & 36 & 41 & 110 \\
\hline 78. & Cyrtostachys & $\begin{array}{l}\text { Cyrtostachys } \\
\text { lacca }\end{array}$ & Palem merah & 2 & 17 & - & - & 17 \\
\hline 79. & Elaeis & Elaeis guineensis & Sawit & 2 & 80 & - & 91 & 171 \\
\hline 80. & Licuala & Licuala peltata & Bunga kipas & 2 & - & - & 3 & 3 \\
\hline 81. Pandaceae & Pandanus & Pandanus odorus & Pandan wangi & 1 & - & 35 & - & 35 \\
\hline 82. Piperaceae & Piper & Piper betle & Sirih & 1 & 35 & 40 & 44 & 119 \\
\hline 83. Rubiceae & Gardenia & Gardenia carinita & Kaca piring & $\begin{array}{c}2 \text { dan } \\
3\end{array}$ & - & 3 & 31 & 34 \\
\hline 84. & Morinda & Morinda citrifolia & Mengkudu & 3 & 1 & 1 & - & 2 \\
\hline 85. & Ixora & Ixora macrothysa & Soka & $\begin{array}{l}1 \text { dan } \\
2\end{array}$ & 25 & 37 & 20 & 82 \\
\hline 86. Rutaceae & Citrus & $\begin{array}{l}\text { Citrus } \\
\text { aurantifolia }\end{array}$ & Jeruk nipis & $\begin{array}{c}2 \text { dan } \\
3\end{array}$ & 13 & 11 & 9 & 33 \\
\hline 87. & & Citrus hystrix & Jeruk purut & 2 & - & - & 7 & 7 \\
\hline 88. & & Citrus maxima & Jeruk bali & $\begin{array}{c}2 \text { dan } \\
3\end{array}$ & 1 & - & - & 1 \\
\hline 89. & Murraya & $\begin{array}{l}\text { Murraya } \\
\text { paniculata }\end{array}$ & Kemuning & 2 & 3 & - & - & 3 \\
\hline 90. Rosaceae & Rosa & Rosa sp & Mawar & 1 & 11 & 17 & 23 & 51 \\
\hline 91. Solanaceae & Solanum & $\begin{array}{l}\text { Solanum } \\
\text { melongena }\end{array}$ & Terong & 1 & 18 & 27 & 13 & 58 \\
\hline 92. & & Solanum torvum & Rimbang & 2 & - & 7 & - & 7 \\
\hline 93. & Capsicum & $\begin{array}{l}\text { Capsicum } \\
\text { frutencens }\end{array}$ & Cabai rawit & 1 & 14 & 85 & 20 & 119 \\
\hline 94. Sapindaceae & Euphoria & $\begin{array}{l}\text { Euphoria } \\
\text { longana }\end{array}$ & Kelengkeng & 3 & 2 & 7 & 9 & 18 \\
\hline 95. & Pometia & Pometia pinnata & Matoa & 3 & 4 & 10 & - & 14 \\
\hline 96. & Nephelium & $\begin{array}{l}\text { Nephelium } \\
\text { lappaceum }\end{array}$ & Rambutan & 3 & 13 & 19 & 21 & 53 \\
\hline 97. Sterculiaceae & Dombeya & $\begin{array}{l}\text { Dombeya } \\
\text { spectabilis }\end{array}$ & Waru landak & 2 & 5 & - & - & 5 \\
\hline 98. & Theobroma & Theobroma cacao & Coklat & 2 & 19 & 28 & 5 & 52 \\
\hline 99. Sapotaceae & Achras & Achras zapota & Sawo & $\begin{array}{c}2 \text { dan } \\
3\end{array}$ & 7 & 14 & 5 & 27 \\
\hline 100. Thymelaeaceae & Aquilaria & $\begin{array}{l}\text { Aquilaria } \\
\text { malaccensis }\end{array}$ & Gaharu & 3 & 25 & 17 & - & 42 \\
\hline 101. Turneraceae & Turnera & $\begin{array}{l}\text { Turnera } \\
\text { trioniflora }\end{array}$ & Turnera & 1 & 17 & 25 & - & 42 \\
\hline 102. Verbeceae & Clerodendrom & $\begin{array}{l}\text { Clerodendron } \\
\text { scandens }\end{array}$ & $\begin{array}{l}\text { Nona makan } \\
\text { sirih }\end{array}$ & 2 & - & 3 & - & 3 \\
\hline 103. Zingiberaceae & Curcuma & $\begin{array}{l}\text { Curcuma } \\
\text { domestica }\end{array}$ & Kunyit & 1 & 60 & 72 & 20 & 152 \\
\hline 104. & Alpinia & Alpinia galangal & Lengkuas & 2 & 71 & 60 & 29 & 160 \\
\hline 105. & Kaemferia & Kaemferia & Jahe & 1 & 30 & 27 & 5 & 62 \\
\hline
\end{tabular}


Yulianti, D., Purnama, AA., Brahmana, EM. 2018. Keanekaragaman Tanaman Pekarangan di Desa Tambusai Timur Kecamatan Tambusai Kabupaten Rokan Hulu Provinsi Riau. Sainstek : Jurnal Sains dan Teknologi. 10 (1) : 13-19

\begin{tabular}{|c|c|c|c|c|c|c|c|c|c|}
\hline \multirow{2}{*}{ No } & \multicolumn{3}{|c|}{ Taksonomi } & \multirow{2}{*}{ Nama Lokal } & \multirow{2}{*}{ Strata } & \multicolumn{3}{|c|}{ Stasiun } & \multirow{2}{*}{ Jumlah } \\
\hline & Famili & Genus & Spesies & & & 1 & 2 & 3 & \\
\hline 106 & & Zingiber & $\begin{array}{l}\text { galangal } \\
\text { Zingiber } \\
\text { officinale }\end{array}$ & Kencure & 1 & 14 & 11 & 7 & 32 \\
\hline 107 & & & $\begin{array}{l}\text { Zingiber } \\
\text { spectabile }\end{array}$ & Kincong & 2 & - & 15 & - & 15 \\
\hline Tota & & & & & & 1.645 & 1.929 & 1.339 & 4.913 \\
\hline
\end{tabular}

Tabel 2. Indeks Keanekaragaman Tanaman Pekarangan di Desa Tambusai Timur Kecamatan Tambusai Kabupaten Rokan Hulu.

\begin{tabular}{cccl}
\hline No & Lokasi & Indeks keanekaragaman & \multicolumn{1}{c}{ Kreteria } \\
\hline 1. & Stasiun 1 & 4,65 & Keanekaragaman tanaman pekarangan tinggi \\
2. & Stasiun 2 & 4,90 & Keanekaragaman tanaman pekarangan tinggi \\
3. & Stasiun 3 & 3,72 & Keanekaragaman tanaman pekarangan tinggi \\
\hline
\end{tabular}

\section{KESIMPULAN}

Berdasarkan hasil penelitian dapat disimpulkan bahwa terdapat 4.913 individu tanaman pekarangan di Desa Tambusai Timur Kecamatan Tambusai Kabupaten Rokan Hulu Provinsi Riau dengan indeks keanekaragaman tanaman tergolong tinggi dengan nilai pada stasiun $1(4,65)$, stasiun $2(4,90)$ dan stasiun 3 $(3,72)$. Dari hasil penelitian ditemukan 107 spesies tanaman pekarangan yang tergolong kepada 53 famili dan 96 genus yang diperoleh dari 3 stasiun.

\section{DAFTAR KEPUSTAKAAN}

Corner, E. J. H., \& Watanabe. (1969). Collection Of Illustrate Tropical Plants. Kyoto.

Indriyanto. (2006). Ekologi Hutan. Jakarta: Bumi Aksara.

Mukarlina., Linda, R., \& Nurlaila, N. (2014).
Keanekaragaman Jenis Tanaman Pekarangan di Desa Phauman Kecamtan Sengah Temila Kabupaten Landak, Kalimantan Barat. Saintifika, 16(1), 6-59.

Odum, E. P. (1998). Dasar-Dasar Ekologi. Terjemah: Samingan, T. Gajah Mada University. Press. Yogyakarta.

Pendong, E. F., \& Arrinjani. (2004). Keanekaragaman Tanaman Pekarangan Di Kota Tomonon, Sulawesi Utara. Biosmart, 6(1), 44-45.

Yarni., Yesnibar, \& Bangun, S. (2012). Manfaat Tanaman Pekarangan Daerah Condet, Serangsang Sawah dan Manggarai di Dki Jakarta. Jes Bio. 1(1): 34-38. Jes Bio, 1(1), 34-38.

Zulkarnain, H. (2010). Dasar-Dasar Horokultura. Jakarta: Bumi Aksara. 